\title{
The Ethnic Identity in the Social Identity Structure of the Residents of Belarus and Russia
}

\author{
Natallia Leonidovna Balich ${ }^{1} \&$ Victoria Nikolaevna Mukha ${ }^{2}$ \\ ${ }^{1}$ Institute of Sociology of National Academy of Sciences of Belarus, Minsk, Republic of Belarus \\ ${ }^{2}$ Kuban State Technological University, Krasnodar, Russian Federation \\ Correspondence: Victoria Nikolaevna Mukha, Kuban State Technological University, Moskovskaya Street, 2, \\ Krasnodar, 350072, Russian Federation. E-mail: v.mukha@bk.ru
}

\author{
Received: October 15, 2014 Accepted: October 29, 2014 Online Published: December 30, 2014 \\ doi:10.5539/ass.v11n3p327 URL: http://dx.doi.org/10.5539/ass.v11n3p327
}

\begin{abstract}
The goal of this article is to consider the ethnic identity and interethnic guidelines of the population of Belarus and Russia. The authors conducted empirical studies among the residents of the Republic of Belarus and Krasnodar territory (the Russian Federation) to find out whether people there are ready for interethnic contacts and interactions in various life spheres and how the population of these the two countries perceives the representatives of other ethnic groups. Ethnic identity is considered as an element of the social identity structure which also includes other types of identity (socio-cultural, civil, religious, age-related, etc.).
\end{abstract}

Keywords: social identity, identification, types of identity, ethnic identity, interethnic guidelines

\section{Introduction}

\subsection{Social Identity in the Modern World}

Social, economic and political conditions in Russia and Belarus determine the formation of new forms for social identity and actively influence the evolution and mechanisms of its functioning, that is marked both Russian, and the Belarus researchers (Civil, ethnic and regional identity, 2013; Naumenko, 2012). Changes in social identity are, on the one hand, caused by economic, political and cultural shifts. On the other hand, the social identity itself acts as an important resource and factor of social changes. Thus, there is a need of an integrated cross-country analysis of social identity in its features, its formation processes and its influence upon social life.

The concept of "social identity" is defined by sociologists as "the awareness and experience of one's belonging to various social communities: a small group, a class, a family, a territorial community, an ethno-national group, a nationality, a public movement, a country or the humanity in general" (Yadov, 1995). The feeling of belonging to a social community has significant social and socio-psychological functions: it makes an individual be subordinate to a social group; it provides group protection; and it sets the criteria of assessment and self-assessment.

The general social bases for social identity formation include: the social division of labour; the differences between statuses and roles; the processes of socialization; individual's relations with various communities and groups; and the differences of cultures. Taking into account the diversity of research approaches, the phenomenon of identity remains one of the most complex and multi-valued in social science. This demands new investigations and applied researches aimed at detecting the main trends and formation features of various forms of social identity.

Individual's self-determination by various criteria - sex, age, class, nationality, confession, profession, etc. takes place at different stages through the whole life. An individual determines himself and builds his behaviour in different social contexts differently: it depends on what group he interacts with at a certain moment and what identification is needed to confirm and recognize his membership by the group (Goffman, 2000). At the same time, the individual continues to determine himself as having a certain set of quite constant characteristics which he consider basic and relatively fixed (gender identity, identity with one's family or friends). The set of basic forms of identities is unique for every individual, but all these identities express individual's established internal and external relations with his closest environment. Consequently, social identity should be considered as 
structured and having many forms of manifestation. These forms are determined by the social context of interaction. So, we can say that there is one identity with a great number of forms (Ganeyeva, 2008).

The idea of multilevel identity is based on the concept of "identity matrix" suggested by S. Moskovichi. According to this concept, human identity is a whole set of various identifications. Information is distributed in the matrix under the direction of an identity or a group of identities that dominates at a certain moment. This determines the corresponding angle of worldview. Another guideline is the recognition of multiple identity as a sign of individual's wide circle of social affiliations and the diversity of the structure of his life activity (Moskovichi, 1998). Identity matrix has a social nature. Its configuration and content depend on the peculiarities of society. It rests upon the components of social identity. It is based on values, meanings and guidelines which form various identities: group (family, profession, generation, etc.), physical (appearance, sex and age), political (civil, national, class), spatial, socio-cultural (language, religion, etc.) and others. The matrix characterizes individual's self-identification and includes individual and collective identifications. When identity matrix is used as an analytical category, it allows conceiving the compound structure of individual (personal) and collective identity.

Let us specify some points concerning the interconnection of individual and collective components in the structure of identity.

Collective identity is formed as a result of social interaction and individual's awareness of his belonging to some community or social group. This "generates" the notion of subjective (individual interpretation of collective ideas) with a psychological importance for humans. Such an interaction results in: 1) the community of ideas, values and interests; the understanding of differences between "us" and "them"; 2) psychological guidelines and behavioral patterns regulating the relations with similar and "alien" groups; 3 ) group solidarity determined by the personal attachments of individuals and aimed at maintaining the image in the eyes of various groups including "alien" ones. At that, the feeling of empathy to "friends" determines people's social behaviour, when, in the same circumstances, the conscious feeling-into is a ground for helping or altruistic behaviour. Family, clan, ethnos and nationality are the examples of such collective identities.

So, the self-categorization of an individual always correlates with categorization coming from a social group or other community. Collective identity starts up the mechanisms supraindividual integration and, simultaneously, the isolating mechanisms based on operations carried out, first of all, in the symbolic (consequently - semantic) universe.

In today's society, collective identities are not so much formed spontaneously as constructed purposefully by various groups of intellectual and political elite with the help of appropriate institutions, up-to-date information technologies and communication means. At the same time, collective identities are formed not only under the influence of corporations, government, elites and their identity policy but also as a result of spontaneous changes in popular consciousness which reacts to socio-economic and cultural shifts. Moreover, rapid socio-cultural changes, as a response to them, stir up such "traditional" forms of collective self-identification as religious, national and civilizational ones. That is why, according to A. Tleuzh (Tleuzh, 2010), the construction of collective identity should be considered both a result of sense-making, ideological and propagandistic activity of elites and a spontaneous changing of mass consciousness stereotypes under the influence of political and institutional shifts, and also social, economic and cultural evolution of the modern world.

Collective identity is a generic notion. At the same time, in each person's consciousness, collective identity interacts with individual (personal) identity. Due to this, we can state a dialectic interconnection between individual and collective identity. This dialectics manifests in the fact that person's self-consciousness and its very identity are impossible without looking at oneself from the side and without relating oneself to others and to one or another community.

Besides, they distinguish a kernel and a periphery in the structure of multiple social identity. The kernel of social identity is a certain number of identity forms which help an individual to outline his position in the society regardless of changing social context. The periphery contains forms of identity that, on the contrary, are totally determined by concrete social conditions of interaction.

Numerous sociological investigations (Identity, 2012) show that the identity kernel is formed by the identifications of a human with a circle of everyday communication: family, friends, relatives, colleagues, etc. These social groups allow satisfying individual's vital needs for communication, protection and self-respect. The second level in the structure of identity contains identifications by such factors as generation, nationality, location, status and others. Individual's identifications with constructed nominal social groups, such as the 
humanity, political like-minded people, civil society, etc., i.e. with groups farthest from a certain individual, form the third level in the structure of identity (Ganeyeva, 2008).

\subsection{The Problem of Identity Typology}

In world science, there are various models for the typologization of identities. E. Erikson singles out positive and negative identity (Erikson, 2006); G.H. Mead analyzed the correlation between the social determination of identity and personal freedom (self-determination) and explicates the conscious identity (the presence of reflection) and the unconscious identity (Mead, 1996); J. Habermas unites personal and social identities into the self-identity in his concept of identity balance (Habermas, 2002). According to S. Huntington, such types of identity are, for instance: 1) ascriptive - age, sex, kindred, ethnicity and race; 2) cultural - clan, tribe, language, nationality, religion, civilization; 3 ) territorial - closest environment, village, city, province, region, climate zone; 4) political - fraction, group of interests, ideology, state interests; 5) economic - job, profession, position, work environment, field, economic sector, trade union, class, state; 6) social - friends, clubs, teams, colleagues, social status (Huntington, 2000).

Russian science also worked out many typologies of identity. V.A. Yadov (Yadov, 1995) gives special attention to the typology of social identity kinds by such factor as the specificity of objects for identification: primordial (archaic, traditional) communities and groups (for example, family, settlement or ethno-national communities) and modern communities (for example, production team, communities with one political orientation or with the same views and values, groups with similar social status, the citizens of one state or state unions).

Y.M. Popov proposes to single out macrosocial identity which is an anthroposocietal structure of self-consciousness. It includes subjectively realized and experienced ties, relations, assessments and norms of macrosocial community that determine person's place in the space and time of society. The macrosocial identity is an element of subjective reality. Just as it, the macrosocial identity is in a close historical and dialectic interconnection with society and is formed by social processes. The researcher distinguishes the following basic types of macrosocial identity: civilizational identity, national identity, regional identity, civil identity, supraethnic identity, ethnic identity and race identity (Popov, 2004).

M.N. Guboglo, in his turn, distinguishes four types of identity: primordial-instrumental (gender, family); ethno-cultural (ethnicity and religion); socio-constructivist (professional, social and proprietary); territorial-civil (regional and civil) (Guboglo, 2003).

The described typologies of identity denote one more time the complex and versatile character of the phenomena of social identity.

The sociological scheme of individual's identity formation described by Z. Bauman and the typology of identity proposed by Z.A. Zhade became the operational approaches for the analysis of social identity of population in polyethnic regions. In the opinion of $Z$. Bauman, empathic kinship and intensive contacts create primary groups which provide psychological safety and comfort. They are perceived as initial and objectively given (primordial). Such groups include family and close social circle. The remoteness of people and infrequent (or lacking) contacts promote another type of groups - "Them" and "Aliens". Big groups with no contacts are imaginary communities or secondary groups. They include class, generation, ethnic community and citizenship (Bauman, 2002). The typology of multilevel identity suggested by Z.A. Zhade contains the following levels of identity: ethnic, regional, national, geopolitical and civilizational. These levels are closely interconnected and form a complex system with hierarchical structure (Zhade, 2008).

Let us turn to the analysis of social identity structure of Russians and Belarusians.

\section{Methods}

The results of sociological research carried out in Krasnodar territory (the Russian Federation) and the Republic of Belarus in 2013 by questionnaire became the empirical base. A representative quota sampling with elements of random selection was used to choose respondents. The sample volume in Belarus was 1589 respondents; the sample volume in Krasnodar territory was 1200 respondents.

\section{Results}

\subsection{The Place of Ethnic Identity in the Structure of Social Identity}

S. Huntington noted that cultural identities play an important role in today's world (Huntington, 2000). Ethnic identity belongs to them. Ethnic identity has a special place in the structure of identities because it is basic and self-reinforcing and expresses human's ability to answer the question "Who am I?" towards the ethnic community. 
Ethnic identity takes shape during a long historical path and accumulates the experience of an ethnos in understanding the reality and its place in it. Ethnic identity has various expressive means: language, symbols, idea and folk art fitting in with a certain type of mentality inherent in this very ethnos and culture. Identification by ethnos is a status definiteness which includes three main components: ethnic affiliation, the necessity of positive ethic identity and ethnic safety (Soldatova, 1998). Ethnic identity is not only the acceptance of certain group ideas, the readiness for similar way of thinking (Skorobogataya, 2008) and shared ethnic feelings but also the construction of the system of relations and actions for different situations in ethnic contacts. That is why ethnic identity means the awareness of oneself as a representative of a certain ethnos and culture based on the identification with them and differences from other ethnic groups while adopting the ethnicity and turning it into the ethnic identity.

In human perception, ethnic identity fits to other multiple identities - domestic, role-playing, professional. It does not dominate in the majority of cases. In the periods of unstable political and social system, ethnic identity acts as one of the mechanisms for a steady form of solidarity (Loughlin, 2002). Ethnic identity becomes a psychological ground for ethno-political mobilization, i.e. the willingness of people united by ethnicity to group actions for the sake of national interests (Ryzhova, 2011).

R. Jenkins notes that nominal and real identities should be differentiated. He defines nominal identity as a simple ethnic self-categorization, and he associates real identity with the identity that influences the life of its bearers (Jenkins, 2004).

Ethnic identity includes personal and group identities. Personal identity is described first of all by psychological categories, while group ethnic identity is described by social categories and analyzed on the basis of ethnic communities that an individual belongs to and identifies himself with (Russian Identity, 2007). So, the realization of one's ethnic identity is not something spontaneous. It is to a large extent conditioned by concrete social interests and group needs including political, economic and cultural ones (Drobigeva, 2013).

\subsection{The Hierarchy of Identities of Belarusians and Russians}

The structural analysis of the social identity of people living in Belarus and Krasnodar Krai showed that these nations put civil (living in the same area), national and age identities in the same places of the hierarchy.

Table 1 . The feeling of unity with the following groups and human communities, $\%$

\begin{tabular}{|c|c|c|c|c|c|c|c|c|}
\hline \multirow{2}{*}{ The feeling of unity } & \multicolumn{2}{|c|}{ Fully } & \multicolumn{2}{|c|}{ To some extent } & \multicolumn{2}{|c|}{ Do not feel } & \multicolumn{2}{|c|}{ Undecided } \\
\hline & Belarusians & Russians & Belarusians & Russians & Belarusians & Russians & Belarusians & Russians \\
\hline $\begin{array}{l}\text { With the citizens of the } \\
\text { same country }\end{array}$ & 45.0 & 59.7 & 39.2 & 33.0 & 6.7 & 4.3 & 9.1 & 3.0 \\
\hline $\begin{array}{l}\text { With the people of the } \\
\text { same nationality }\end{array}$ & 35.4 & 54.8 & 45.6 & 34.8 & 6.6 & 6.5 & 12.3 & 3.9 \\
\hline $\begin{array}{l}\text { With the people of the } \\
\text { same confession }\end{array}$ & 26.7 & 38.1 & 42.0 & 38.0 & 12.1 & 14.3 & 19.2 & 9.6 \\
\hline $\begin{array}{l}\text { With the people of the } \\
\text { same generation }\end{array}$ & 40.3 & 51.2 & 43.0 & 36.2 & 5.5 & 7.8 & 11.2 & 4.8 \\
\hline $\begin{array}{l}\text { With the residents of the } \\
\text { CIS }\end{array}$ & 9.6 & 21.5 & 39.9 & 38.7 & 31.7 & 32.4 & 18.8 & 7.4 \\
\hline
\end{tabular}

The national base that forms a kernel of ethnic identity is a significant but not priority factor of association in the view of people in the two countries. Belarusians feel the unity first of all with the residents of Belarus, and Russians feel the unity with Russian citizens. This allows speaking about the civil identity as the dominant one in the system of identifications. Then positions were divided. Russians have ethnic identity at the second place ( $54.8 \%$ of the pollees feel a full unity with the representatives of their ethnic group). Age identity is at the second place in the opinion of Belarusian ( $40.3 \%$ feel a full unity with the people of their generation). At the third place, Belarusians have national identity (35.4\%), and Russians has age identity (51.2\%). Age identity is very topical in the structure of social identity of Russians and Belarusians. This can be easily explained: individual's age characteristics are one of the main socio-demographic indications and an important reference point in social interaction.

Ethnicity is closely connected with religious factor but religious affiliation is not priority in the structure of self-identifications (38.1\% of Russians and $26.7 \%$ of Belarusians) in spite of the fact that both the Republic of 
Belarus and Krasnodar territory are multi-religious. The respondents identify themselves with the residents of the CIS in a less degree: $32.4 \%$ of Russians and $31.7 \%$ of Belarusians have never felt the unity with them (Table 1).

In general, the hierarchies of significant and non-significant identities in the priority structure of Russians and Belarusians, depending on the intensity, can be presented the following way:

Table 2. The hierarchy of identities in the structure of significant priorities

\begin{tabular}{cc}
\hline & The maximal feeling of unity \\
\hline Russians & Types of identity \\
Belarusians & Civil $\rightarrow$ national $\rightarrow$ age-related $\rightarrow$ religious $\rightarrow$ allied \\
Civil $\rightarrow$ age-related $\rightarrow$ national $\rightarrow$ religious $\rightarrow$ allied
\end{tabular}

Table 3. The hierarchy of identities in the structure of absent priorities

\begin{tabular}{cc}
\hline & The feeling of unity (zero degree) \\
\hline Russians & Types of identities \\
Belarusians & Allied $\rightarrow$ religious $\rightarrow$ age-related $\rightarrow$ national $\rightarrow$ civil \\
Allied $\rightarrow$ religious $\rightarrow$ civil $\rightarrow$ national $\rightarrow$ age-related
\end{tabular}

The visa-free regime between Russia and Belarus yields positive results in mutual tourist, economic, labour streams of both states, washing away borders of Russian and Belarus identity and promoting that to international, interstate association in modern integration processes in politico-legal, economic and cultural space. The majority of inhabitants on either side of border associate itself with Russian or Byelorussians have close relatives on the other side of border. It is confirmed with results of research according to which the considerable part of Byelorussians and Russians feel unification with citizens of the next state (Picture 1-2).

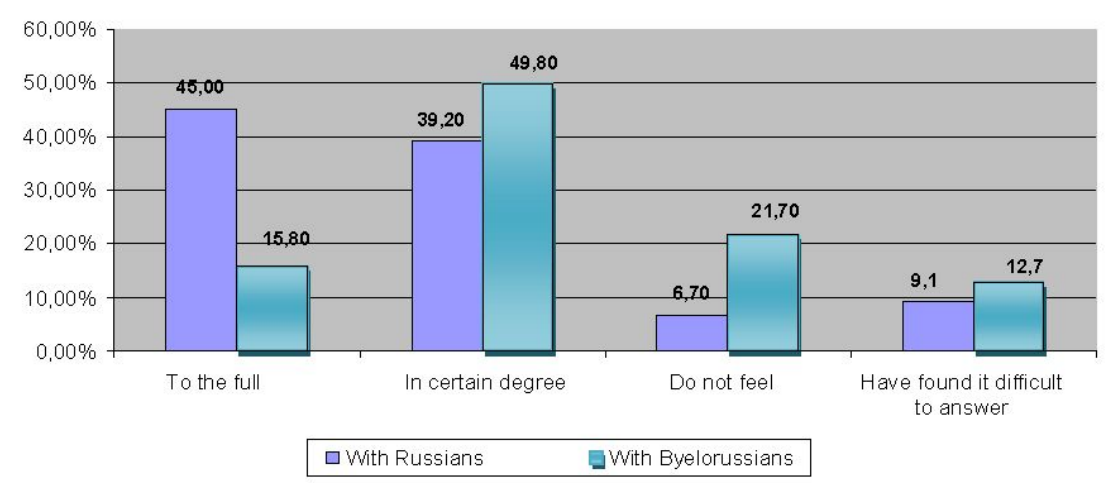

Figure 1. Degree of sensation of unity of Byelorussians with inhabitants of the country and with inhabitants of Russia, \%

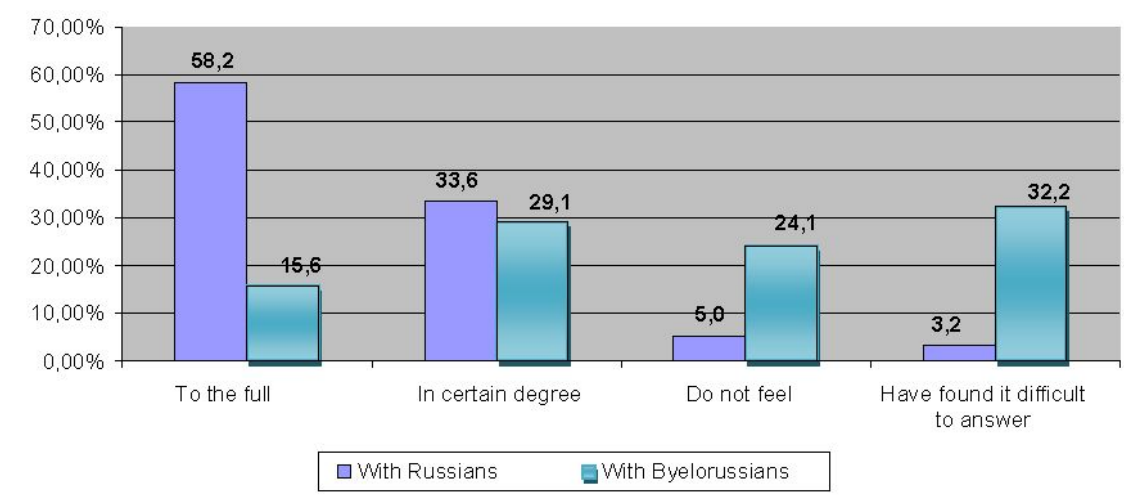

Figure 2. Degree of sensation of unity of Russians with inhabitants of the country and with inhabitants of Belarus, \% 


\section{Discussion}

\subsection{The Significance of Different Types of Identity}

While studying ethnic identity, it was important to consider the subjective significance of different types of identity among the respondents, i.e. whom they believe themselves to be first of all. For this purpose, we included a question with scales in order to find out how deep is the subjective feeling of significance of civil, ethnic and religious identity among Russians and Belarusians. In general, the positions of Russians and Belarusians spread the following way (Table 4).

Table 4. The recognition of different types of identity, $\%$

\begin{tabular}{ccccccccc}
\hline \multirow{2}{*}{ The type of identity } & \multicolumn{2}{c}{ Fully recognize } & \multicolumn{2}{c}{ Recognize to some extent } & \multicolumn{2}{c}{ Do not recognize } & \multicolumn{2}{c}{ Undecided } \\
\cline { 2 - 9 } & Belarusians & Russians & Belarusians & Russians & Belarusians & Russians & Belarusians & Russians \\
\hline Civil & 68.4 & 74.5 & 22.1 & 20.6 & 2.8 & 3.7 & 6.7 & 1.2 \\
Ethnic & 37.4 & 60.7 & 35.5 & 26.9 & 11.9 & 7.2 & 15.2 & 5.2 \\
Religious & 33.4 & 37.2 & 34.5 & 40.7 & 15.1 & 15.0 & 17.0 & 7.1 \\
\hline
\end{tabular}

As the Table shows, $37.4 \%$ of Belarusians and $60.7 \%$ of the residents of Krasnodar Krai, who took part in the research, consider ethnic identity a fully significant characteristic as opposed to civil identity which is fully significant for $68.4 \%$ of Belarusians and $74.5 \%$ Russians. Religious identity does not have a priority $(33.4 \%$ of Belarusians and $37.2 \%$ of Russians) ceding its positions to ethnic identity.

The significance of ethnic identity is explained by the fact that it not only allows an individual to be aware of his uniqueness and imprint the distinctions of his group but also is based on a complex of specific cultural evaluation criteria to assess his own and other people's behaviour. In this connection, it is right to mention such category as tolerance in the ethnic context. Tolerance is especially topical in regions with a high level of interethnic contacts.

\subsection{Interethnic Guidelines}

The topical character of ethnic identity is determined by the specific environment of ethnic contacts: the intensity of interethnic contacts is very high in polyethnic Krasnodar territory. The representatives of different ethnic groups live historically in Krasnodar territory. Today, the representatives of non-Slavic ethnic groups are not isolated individuals but groups with a certain level of ethnic cohesion. This ethnic structure deserves a special attention in the question of interethnic relations which are now tolerant.

The Republic of Belarus is also a polyethnic country. According to the population census of 2009, the representatives of more than 130 nationalities live in the country. About $83 \%$ of them are Belarusians (National Composition of the Population, 2009). Due to this it is very important for ethnic identity of both Russians and Belarusians to be able to accept the representatives of other ethnic groups as interaction partners. In order to evaluate this ability, which also is an indication of interethnic tolerance, we used the modification of social distance scale. It estimates the ability and readiness of respondents to take a person of another ethnic group as a member of family, a friend, a neighbor, a colleague, a community member or a citizen. Respondents were to answer a question which evaluates the desirable degree of affinity with people of other ethnic groups. Scale modification allows presenting the distancing situation the following way (Table 5).

Table 5. The readiness to accept the representatives of another ethnic group, $\%$

\begin{tabular}{|c|c|c|c|c|c|c|c|c|}
\hline \multirow{2}{*}{$\begin{array}{l}\text { The readiness to accept them } \\
\text { as }\end{array}$} & \multicolumn{2}{|c|}{ Agree } & \multicolumn{2}{|c|}{ To some extent } & \multicolumn{2}{|c|}{ Do not agree } & \multicolumn{2}{|c|}{ Undecided } \\
\hline & Belarusians & Russians & Belarusians & Russians & Belarusians & Russians & Belarusians & Russians \\
\hline Close relatives & 40.9 & 15.3 & 31.5 & 32.2 & 15.5 & 45.2 & 12.1 & 7.4 \\
\hline Friends & 52.9 & 36.7 & 29.9 & 43.8 & 7.2 & 16.3 & 10.0 & 3.2 \\
\hline Neighbours & 48.9 & 39.8 & 31.9 & 40.7 & 9.3 & 15.4 & 10.0 & 4.1 \\
\hline Colleagues & 50.1 & 42.1 & 29.2 & 43.6 & 8.2 & 9.9 & 12.5 & 4.5 \\
\hline $\begin{array}{c}\text { Residents of my city, town, } \\
\text { village }\end{array}$ & 49.4 & 41.6 & 31.5 & 41.1 & 8.2 & 13.0 & 11.0 & 4.2 \\
\hline Citizens of my country & 44.7 & 39.4 & 34.1 & 35.1 & 9.9 & 15.6 & 11.3 & 5.7 \\
\hline Only tourists in my country & 29.8 & 31.0 & 27.6 & 27.4 & 26.8 & 27.7 & 15.9 & 14.0 \\
\hline $\begin{array}{l}\text { I do not want to see them in } \\
\text { my country }\end{array}$ & 9.8 & 15.1 & 14.8 & 19.0 & 55.5 & 45.9 & 20.0 & 20.0 \\
\hline
\end{tabular}


The scales of different contacts made it possible to find out the main forms of interaction and detachment among Russians and Belarusians.

The answers of Belarusians show that these people are ready to accept the representatives of another ethnic group mostly as friends $(52.9 \%)$, colleagues $(50 . \%)$, residents of the region $(49.4 \%)$, neighbours $(48.9 \%)$ and citizens of their country (44.7\%). The social distance increases when it comes to family sphere: only $40.9 \%$ are ready to see a representative of another ethnic group as a close relative, and $15.5 \%$ are not ready to do it. $29.8 \%$ would like to see the representatives of another ethnic group only as tourists. The rarest answer "I do not want to see them in my country" was chosen by $9.8 \%$ of respondent.

Among the inhabitants of Krasnodar territory, $15.3 \%$ of respondents are ready to accept a person of another nationality as close relatives without reserve; $32.2 \%$ are ready for it to some extent which is a quite high indication in polyethnic environment. In other spheres (friendship, neighbourhood, business, etc.), the distance reduces significantly. The rarest answer (15.1\%) is "I do not want to see them in my country". In general, the social distance increases in direct interpersonal relations (close relative or friend), while it reduces in indirect intergroup contacts (citizen or tourist). The majority of respondents from Krasnodar territory display a high readiness for interethnic contacts.

As the Table shows, there is a relative indifference concerning the ethnic criterion among Russians and Belarusians in case when the interaction takes place in the framework of companionship, business, neighbourhood and joint residence. However, both Belarusians and the inhabitants of Krasnodar territory display a high withdrawal in family relationships. In fact, this is a natural desire of consolidation by ethnicity.

The comparative characteristics of Russians and Belarusians allowed evaluating the degree of their readiness for an intercultural dialogue and communications. According to the research, the highest level of tolerance is detected in the group of Belarusians.

\section{Findings}

Summarizing the analysis of empirical data, we can state the actualized ethnic identity of people living in Belarus and Krasnodar territory where conflict-free interethnic communications and ethnic tolerance remain in spite of polyethnic population. This is to a large extent caused by the ethnic diversity and the absence of ethnic fanaticism in these regions. In general, the results of the research are of a certain scientific interest for ethnic sociology and conflict resolution studies. The results can be used for developing further measures aimed at greater integration of the peoples of Russia and Belarus.

\section{Acknowledgements}

The research was performed within the framework of the joint project "The Features of Social Identity in the Context of Modern Integration Processes in the Union of Belarus and Russia" supported by the Belarusian Republican Foundation for Fundamental Research (contract \# G12R-007 of 15.04.2012) and the Russian Humanitarian Scientific Foundation (project \#12-23-01000 a(m)).

\section{References}

Bauman, Z. (2002). The Individualized Society. Moscow: Logos.

Drobigev, L. M., \& Rosspan, M. (2013). Civil, ethnic and regional identity: Yesterday, today, tomorrow (p. 485).

Drobigeva, L. M. (2013). Ethnity in sociopolitical space of the Russian Federation. Experience of 20 years (p. 336). M.: New chronograph.

Ericson A. (2006). Identity: a youth and crisis. Interp. from English (p. 342). M.: Flinta.

Ganeyeva, Y. I. (2008). The Problem of Social Identity: the Essence and Formation Conditions, The Review of the Lobachevsky University of Nizhny Novgorod. The Social Sciences Series, 1, 39-45.

Goffman, E. (2000). The Presentation of Self in Everyday Life. Moscow: Canon-Press.

Guboglo, M. N. (2003). The Identification of Identity. Ethno-Sociological Essays. Moscow: Science.

Habermas, J. (2002). European National State: Its Gain and Limits. The Past and Future of Sovereignty and Citizenship, Nations and Nationalism. Moscow: Praksis.

Huntington, S. (2000). Who are we? The Challenges to America's National Identities. N.Y.

Jenkins, R. (2004). Social Identity. London and New York: Routledge. http://dx.doi.org/10.4324/9780203463352

Loughlin, J. (2002). Nation, state, and Region in Western Europe. Culture: Building Stone for Europe 2002: Reflections and Perspectives, Brussels. 
Mead, G. (1996). The Internalized Others and the Self. American Sociological Thought. Moscow.

Moscovichi, S. (1998). The Age of Crowds. The Historical Treatise on Mass Psychology. Moscow: The Centre of Psychology and Psychotherapy.

Naumenko, L. I. (2012). The Belarus identity. The maintenance. Dynamics (p. 205). Socially-demographic and regional specificity. Minsk: Byelorussian science.

Popov, M. Y. (2004). The Anthropology of Sovietism. The Philosophical Analysis (Ph.D. Thesis). Stavropol.

Russian Identity in Sociological Dimension. Analytical Report. (2007). Moscow: Russian academy of Sciences.

Ryzhova, S. V. (2011). Ethnical Identity in the Context of Tolerance. Moscow: Alpha-M.

Skorobogataya, A. A. (2008). Ethnic Identity and Cross-cultural Interaction in Northern Bashkiria. Moscow.

Soldatova, G. U. (1998). The Psychology of Interethnic Tension. Moscow.

The Identity and Consolidation Resource of People Living in the Republic of Sakha (Yakutia). (2012). Moscow: The Russian Academy of Sciences.

The National Composition of the Population. Citizenship. The Population Census of 2009. The National Statistic Committee of the Republic of Belarus. Retrieved from www.belstat.gov.by/uploads/file/GU_demogr/5.80.pdf

Tleuzh, A. K. (2010). Constructing Russian Collective Identity. Moscow: Social and Humanitarian Knowledge.

Yadov, V. A. (1995). Social and Socio-psychological Mechanisms of Person's Social Identity Formation, The World of Russia, 3-4, 158-181.

Zhade, Z. A. (n. d.). Russian Identity as a Multilevel Structure. Retrieved from www.elcom.ru/ human/2008ns/ 07jza.htm.

\section{Copyrights}

Copyright for this article is retained by the author(s), with first publication rights granted to the journal.

This is an open-access article distributed under the terms and conditions of the Creative Commons Attribution license (http://creativecommons.org/licenses/by/3.0/). 